\title{
Extensive Survay on Torque Controlling of PMBLDC- Motor using Conventional \& Artificial Intelligent Controllers
}

\author{
Amina Salim ${ }^{1}$ \\ B.Tech Student, EEE Department \\ Musaliar College of Engineering \\ Trivandrum, Kerala, India \\ Mohammed Shakir ${ }^{3}$ \\ B.Tech Student, EEE Department \\ Musaliar College of Engineering \\ Trivandrum, Kerala, India \\ Thaha H. S \\ Assistant Professor, EEE Department \\ Musaliar College of Engineering \\ Trivandrum, Kerala, India
}

\author{
Azya. $\mathrm{N}^{2}$ \\ B.Tech Student , EEE Department \\ Musaliar College of Engineering \\ Trivandrum, Kerala, India \\ Anseena A Sharafudeen ${ }^{4}$ \\ B.Tech Student, EEE Department \\ Musaliar College of Engineering \\ Trivandrum, Kerala, India \\ Shimi Mohan ${ }^{6}$ \\ Associate Professor, EEE Department \\ Musaliar College of Engineering \\ Trivandrum, Kerala, India
}

\begin{abstract}
Permanent magnet Brushless DC Motor has been commonly utilized in fields that necessitate high fidelity and specific control, owing to its simple structure, high power density, high efficiency, high starting torque, long operating life, and prolonged ranges of speed. While considering of the drive part of the motor, the most significant part is commutation control. During commutation, they generate some high torque ripples which are caused by non-ideal commutation currents in the stator windings which confines its application, exclusively at low-voltage fields. In this paper we compare the efficiency of conventional and artificial intelligence in torque controlling of permanent magnet brushless DC motor. It presents the study, analysis and comparison of the PI controller, Genetic Algorithm, Artificial Neural Network and Fuzzy Logic Controller. Disadvantages of PI controller can be overcome further by the advanced genetic algorithm based controller. This system has adaptive voltage reference and controls its speed. But its settling time is more. Thus the disadvantage of genetic algorithm based controller can be overcome further by the artificial neural controller. It has excellent flexibility and adaptability as well as high precision and good robustness is obtained. But it's settling time is also larger. Thus the disadvantage of the three controllers can be overcome further by Fuzzy Logic Controller and it has settling time of torque is too small. So it is observed that Fuzzy Logic based controller give better response than other controllers for the torque control DC Motor.
\end{abstract}

Keyword: PI controller, Genetic algorithm, Artificial Neural Network, Fuzzy logic controller, PMBLDC, Torque

\section{INTRODUCTION}

Conventional DC motors are highly efficient due to which it is suitable to use as servomotors. However, there drawbacks are that they need a commutator and brushes. Constant maintenance is required since they are subjected to wear. When solid state switches are used to implement the functions of commutator and brushes, maintenance free motors were realized. These motors are known as brushless
DC motors. The magnet in the brushless motor and DC commutator motor has the same function. The advantage of brushless configuration is the removal of brushes. Brush maintenance is no longer required.

Brushless DC motors are electronically commutated which lead them effectively maintenance free motor. Application of BLDC motor is rapidly increasing due to their features like high efficiency, higher power density, high torque to weight ratio and easy to control over a wide range of speed. Fluctuating loads, continues loads and position control in the field of industrial control, automotive, fitness care apparatus, aviation, automation schemes etc. are their applications.

In BLDC motors stator consisting of three-phase distributed winding on the stator and permanent magnets on the rotor. Unlike conventional DC motors, stator winding remains stationary and rotor rotates. It is necessary to control the motor to obtain the smooth response of torque and speed with less ripple content. The inductance effect of winding mainly influences the shape of trapezoidal back emf and rectangular stator currents of the motor.Ripple in torque will result due to the deviation of stator current from its ideal rectangular shape. Acoustic noise and vibration will be the result.

This is the main reason for the constrained application of BLDC motor.. Without costly motor controlled valves, the torque control ensure linear stops to prevent water hammer in pump applications. Torque can be controlled by conventional and artificial intelligent type controllers. This paper presents the study and analysis of the PI, genetic algorithm, neural network, fuzzy control system applying to Permanent-Magnet Brushless DC (BLDC) motor. Conventional and artificial intelligent based control methods are compared in this paper. 


\section{PRINCIPLE OF OPERATION PRINCIPLE OF OPERATION}

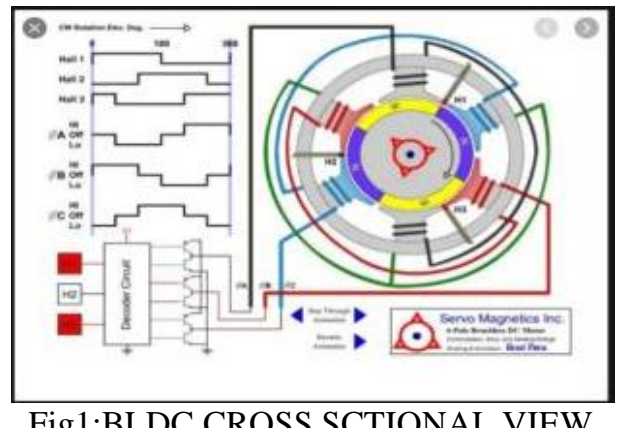

When DC supply is given to the motor, the armature winding draws a current. The current distribution within the stator armature winding depends upon the rotor position. The mmf perpendicular to the permanent magnet field is set up. Then the armature conductor experiences a force. The force develops torque in the rotor. If this torque is more than the opposing frictional and load torque, the motor starts. It is self-starting motor.as the motor picks up speed, there exists a relative angular velocity between the permanent magnet field and armature conductors.

As per faradays law of electromagnetic induction, an emf is dynamically induced in the armature conductors. This back emf as per Lenz's law opposes the cause of armature current and is reduced. As a result the developed torque reduces. Finally the rotor will attain a steady speed when the developed torque is exactly equal to the opposing frictional load torque. Thus the motor attains a steady state condition. When the load-torque is increased, the rotor speed tends to fall. As a result the back emf generated in the armature winding tends to get reduced. Then the current drawn from the mains is increased as the supply voltage remains constant. More torque is developed by the motor. The motor will attain a new dynamic equilibrium position when the developed torque is equal to the new torque. Then the power drawn from the mains $\mathrm{V}^{*} \mathrm{I}$ is equal to the mechanical power delivered $\mathrm{Pm}=\omega \mathrm{T}$ and the various losses in the motor and in the electronic switching circuitry.

\section{TORQUE CONTROLLING METHODS}

\section{PI CONTROLLER}

In wide range of Industrial applications Brushless DC Motors are used for easy control and high power density. Here brushless DC motor model is designed with proportional integral controller. The PI controller is used to control the speed of the brushless DC motor. On the other hand parameters like Back EMF, current, speed and torque are evaluated for the designed models of BLDC motor. Due to the easy implementation and simple control structure the convectional PI controller are used in industries [2].In industrial system PI is a control loop feedback mechanism. Actually between measured processes variable and desired set point error exist. So to correct that error Proportional integral controller is used in industries.

The proportional mode and integral mode are two separate modes involved in proportional integral mode calculation. The reaction to the current error is calculated by Proportional mode and reaction to the recent error is calculated by integral mode. So the sum of these two modes output is considered as corrective action to the control element and PI controller is implemented [2].The reason why conventional controller has low efficiency such as PI controller because the overshoot is too high from the set point and it may takes delay time to get constant and sluggish response due to sudden change in load torque and the sensitivity to controller gains $\mathrm{Ki}$ and Kp [4].In several applications brushless DC motors are utilized and the torque ripples cause major impact on the performance of those applications. Previously numerous methods are used to improve the controller performance by reducing the ripples in BLDC motors [1].

Fig shows the Proportional-Integral (PI) controller block diagram. The speed error EN between the reference speed NR and the actual speed $\mathrm{N}$ of the motor is fed to the PI controller, and the $\mathrm{K} 1$ and $\mathrm{K} 2$ are the proportional end integral gains of the PI controller [4].

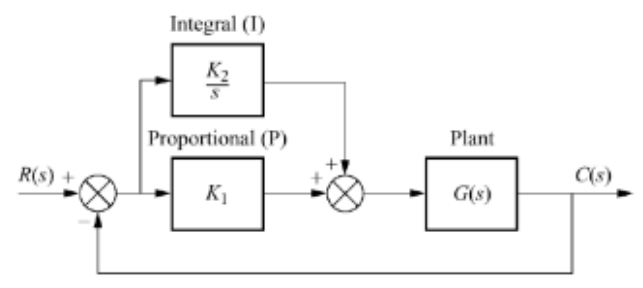

Fig 1.1: Block diagram of PI Controller

\section{Torque Characteristics}

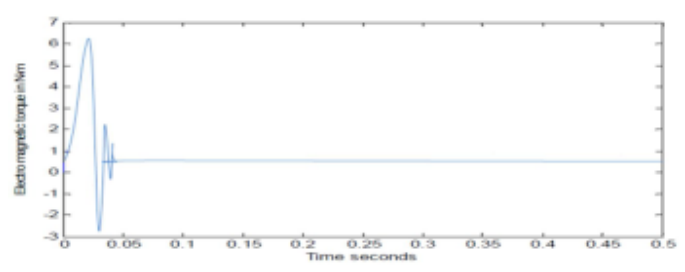

Fig 1.2: Torque characteristics

The output is that the Electromagnetic torque is set as $700 \mathrm{rpm}$ with 0.05 seconds at rest. At the same time the initial phase back electromotive force of the BLDC motor is zero. However, the PI controller has some disadvantages such as: high starting overshoot, sensitivity to controller gains and sluggish response due to sudden load disturbance [4]. It testifies that this method is not only robust, but also can 'improve dynamic performance of the system.

\section{GENETIC ALGORITHM}

Brushless DC motor torque ripple reduction has been the main issue in servo driving systems in which the speeds of fluctuation, vibration, and acoustic noise should be minimized. Most methods for suppressing torque ripples usually require Fourier series, analysis, finite element analysis or least-mean-square minimization. These 
methods might lead to errors during complex Fourier series analysis and cost much calculation time. This presents a new method to improve torque ripple based on the Genetic Algorithm.

The method depends on Genetic Algorithms to search for the Fourier coefficients of three-phase stator currents for the given back-EMF waveforms. These Fourier coefficients can then be used to recompose three-phase optimum current commands for three-phase balanced brushless DC motor driving. The torque ripple must therefore be expected to improve in this way if stator currents are perfectly achieved. The validity and practical applications of the proposed method are verified from experiments using the TMS320F2812 DSP.

In the experimental structure, the three-phase optimum current commands and the measured three-phase back-EMFs are set up as the tables. They are obtained according to the rotor angle and speed information from the encoder. The experimental results can prove that the proposed method provides a simple and efficient way to obtain three-phase optimum stator currents for the given back-EMF waveforms and the minimum torque ripple will also be acquired [8].

Genetic Algorithms (GA.s) are a stochastic global search method that mimics the process of natural evolution. It is one of the methods used for optimization. John Holland formally introduced this method in the United States in the 1970at the University of Michigan. The continuing performance improvements of computational systems have made them attractive for some types of optimization[3] [6].

The genetic algorithm starts with no knowledge of the correct solution and depends entirely on responses from its environment and evolution operators such as reproduction, crossover and mutation to arrive at the best solution. By starting at several independent points and searching in parallel, the algorithm avoids local minima and converging to sub optimal solutions[3].

Genetic Algorithms are search and optimization techniques inspired by two biological principles namely the process of natural selection and the mechanics of natural genetics. GAs manipulates not just one potential solution to a problem but a collection of potential solutions. This is known as population. The potential solution in the population is called chromosomes. These chromosomes are the encoded representations of all the parameters of the solution. Each Chromosome is compared to other chromosomes in the population and awarded beneficial Characteristic to their offspring.

To encode better solutions, the GA will use genetic operators or evolution operators such as crossover and mutation for the creation of new chromosomes from the existing ones in the population. This is achieved by either merging the existing ones in the population or by modifying existing chromosomes. The selection mechanism for parent chromosomes takes the fitness of the parent into account. This will ensure that the better solution will have a higher chance to procreate and donate their
There are three main stages of a genetic algorithm. These are known as reproduction, crossover and mutation. GAs search algorithms which are developed using principles inspired by natural genetics to solve[3] [6].

GAs three major operators: Selection, crossover, and mutation, in addition to the four control standards include: population size, selection, crossover, and mutation rate. The idea is to maintain the population of chromosomes (representing the solution of candidate for the concrete problem being solved) that a process develops over time through of competition and controller variation. As in GA described the flow chart blower [6].

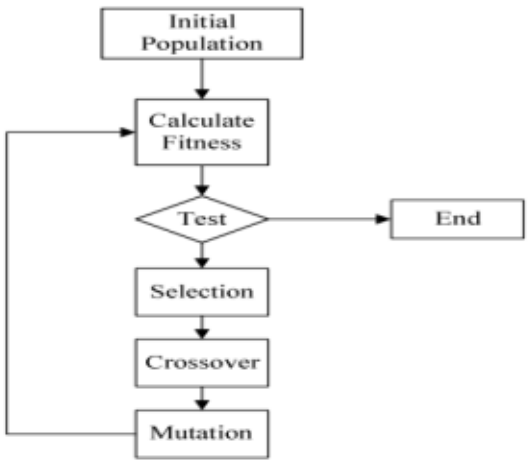

Fig 2.1: Block diagram of Genetic Algorithm

Initial Population-GA starts with generating a random population of $\mathrm{n}$ chromosomes (suitable solutions for the problem). The population is composed by binary or real coded string chromosomes[3] [6].

Calculate Fitness-Evaluate the fitness value of each chromosome in the population[3] [6].

Test-If the end condition is satisfied, stop, and return the best solution in the current population. New population If the condition is not satisfied, a population is generated by following the steps below until a new population is complete [6].

1. Selection-Selects two parent chromosomes from a population according to their fitness (the better

fitness, the bigger chance to be selected) [6].

2. Crossover-With a crossover probability, cross over the parents to generate new offspring. If no crossover was performed, the offspring is copied exactly the parents [6].

3. Mutation-with a mutation probability, mutate new offspring at each locus [6].

\section{TORQUE RESPONSE}

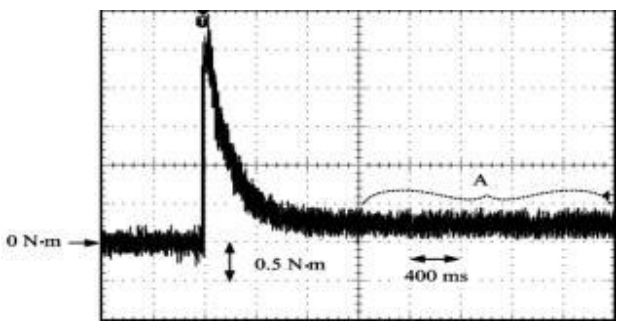

Fig 2.2: Torque Response 


\section{ARTIFICIAL NEURAL NETWORK}

The conventional controllers exhibit degraded performance due to this change in the internal parameters of the motors. This has led researchers to explore intelligent and adaptive controllers that can perform satisfactorily under a wide range of circumstances. Artificial Neural Networks (ANN) have a tremendous scope in control system applications due to the numerous advantages offered by them. Its high learning trait and nonlinear mapping features offer a desired non-linear mapping for an electric drive without going into the system complexity [10]. The Neural Network controller has proved to be an efficient controller to perform a high performance speed control. The predictive controller consists of an optimization algorithm which changes the Neural Network weights such that the drive catches up with the reference speed [12].

Conventional PI and PID controllers require accurate mathematical models of the systems in which they are implemented. For most of the electric drive applications, unknown conditions such as saturation and disturbances lead to unacceptable tracking performance. So intelligent control methods such as Artificial Neural Networks (ANN) are adopted to solve these problems of electric drives. Unknown nonlinear dynamics which are difficult to model such as noise and disturbances can be recognized by an intelligent trained neural network. The block diagram of a closed loop speed control of a PMBLDC motor using Artificial Neural network is shown in Fig: 1.

The closed loop system consists of a DC source, a three phase inverter, PMBLDC motor and an ANN controller. The three phase inverter supplies the three phase ac currents to the stator windings of the PMBLDC motor. An ANN speed controller is employed to maintain the speed constant irrespective of the changes in the input DC voltage. ANN controller is used in the feedback control path to keep the output speed constant to $3000 \mathrm{rpm}$. Simulation is done in MATLAB SIMULINK environment after training the neural network.

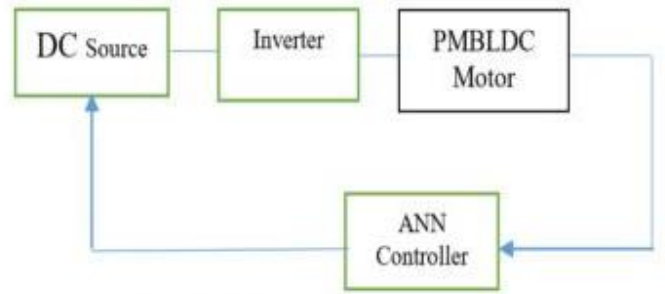

Fig 3.1: Block Diagram of Artificial Neural Network

Artificial Neural Networks (ANN) is a parallel computational system consisting of many simple processing elements connected together in a specific way to perform a particular task. A typical neural network has millions of artificial neurons called units arranged in a series of layers, each of which connects to layers on either side. Input layer receive information from the outside world and the output layer respond to the information that is learned. Between the input layer and the output layer is the hidden layer. The inputs are multiplied by weights and then computed by a mathematical function which determines the activation of the neuron given by Fig: 3.2 .

The higher a weight of an artificial neuron is, the stronger will be the input which is multiplied by it. By adjusting the weights of an artificial neuron we can obtain the outputs we want for specific outputs. An ANN consists of thousands of neurons, which makes it very difficult to compute the weights by hand. So different algorithms are used to adjust the weights of ANN inorder to obtain the desired output from the network. This process of adjusting the weights is called learning or training[14].

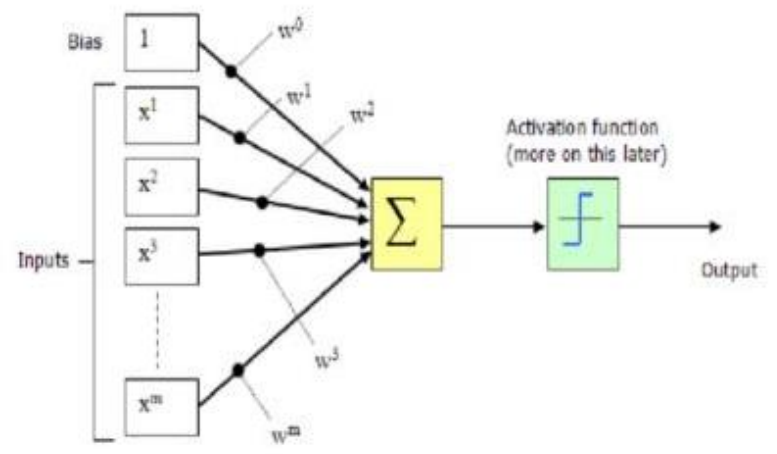

Fig 3.2: Neural Network Model

The simplest kind of artificial neural network is a single-layer perceptron feed-forward neural network. In this network the information moves in only one direction, forward, from the input nodes directly to the outputs through a series of weights. There are no cycles or loops in the network [12]. Multi-layer networks use a variety of learning algorithms, the most common being backpropagation algorithm.

The algorithm trains feed-forward multi-layer neural networks for a given set values .of input patterns with known classifications. When each sample set is presented to the network, the network examines its output response with the sample input pattern. The output response is then compared with the desired output and the error value is calculated. Based on the error, the connection weights are adjusted. Here the weight adjustment is done through mean square error of the output response to the sample input. The set of these sample patterns are repeatedly presented to the network until the error value is minimized [11].

\section{NEURAL NETWORK - MODEL PREDICTIVE CONTROL}

Neural Networks have been used for non-linear system identification in the recent years and it has proved to be extremely successful. Model Based Predictive Control (MBPC) is the use of a neural network model of a non-linear plant to predict the future output trajectory of the system. Neural Predictive Control is a type of model based predictive control where the model for predictions is a neural model.

The block diagram of the Neural Predictive Controller is shown in Fig: 3.3, where YP is the plant output and $\mathrm{Ym}$ is the neural network output and $\mathrm{u}$ is the control dc voltage input applied to the plant[11]. 


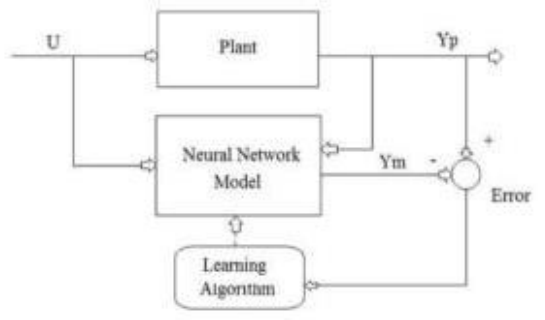

Fig 3.3: Block Diagram of Neural Predictive Controller

\section{FUZZY LOGIC CONTROLLER}

Fuzzy logic controller which is presented by Zadeh in 1965, is a new controller [4]. Besides that, fuzzy logic controller is more efficient from the other controller such as proportional-integral (PI) controller. The comparison between them is needed to compare what the controller is efficient[11] [4]. The reason why conventional controller low efficiency such as PI controller because the overshoot is too high from the set point and it may takes delay time to get constant and sluggish response due to sudden change in load torque and the sensitivity to controller gains $\mathrm{Ki}$ and $\mathrm{Kp}$ [4].

To simplicity of control system, fuzzy logic controller is being introduced. It may reduce the transient at the starting point and make it constant in short time of period. Therefore, the system would be more efficient to control the speed of BLDC motor [4]. Recently, fuzzy logic employing the logic of approximate reasoning continues to grow in importance, as it provides an inexpensive solution for controlling ill-known complex systems. Fuzzy controller has already been applied to phase controlled converter dc drive, linear servo drive and induction motor drive [4].

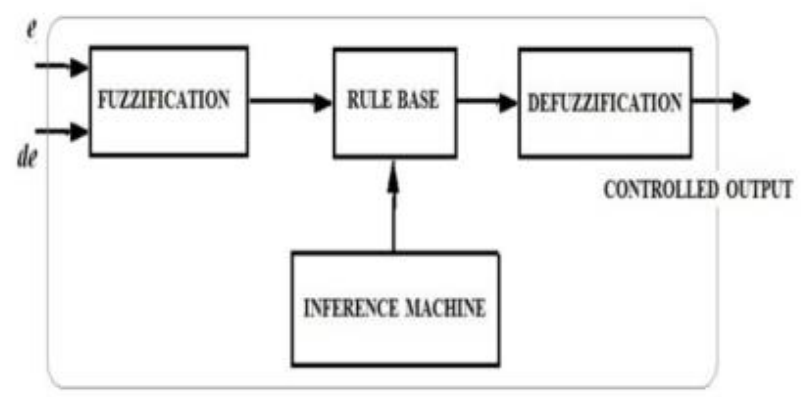

Fig 4.1: Block Diagram of Fuzzy Logic

Figure shows the basic structure of fuzzy logic controller. Fuzzy logic's linguistic terms are most often expressed in the form of logical implications, such as If-Then rules. These rules define a range of values known as fuzzy membership functions [4][11]. Fuzzy membership functions may be in the form of triangle, a trapezoid, a bell as shows in figure 1, or another appropriate form.

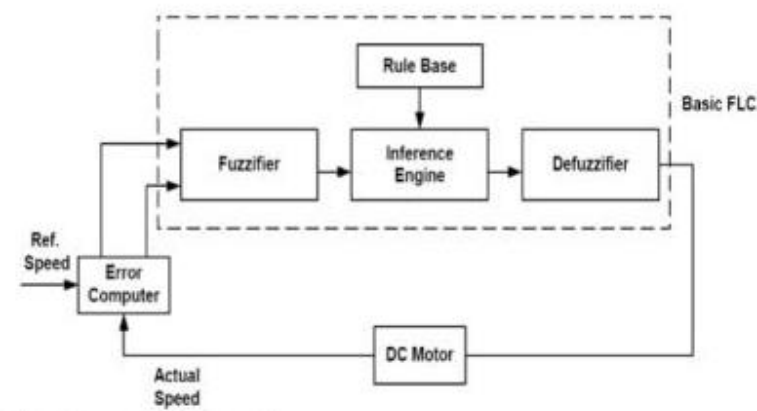

Figure 4.2: Fuzzy logic controller

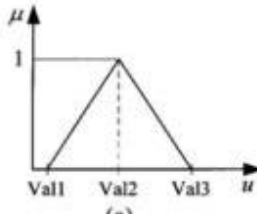

(a)

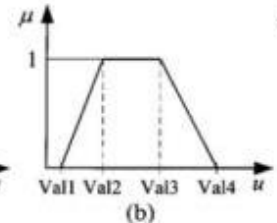

(b)

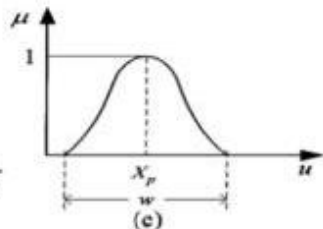

(c)
Figure 4.3: (a) triangle, (b) trapezoid, and (c) bell membership function

The inputs of the fuzzy controller are expressed in several linguistic levels show in figure 3, these levels can be described as positive big (PB), positive medium (PM), positive small (PS), or in other levels. Each level is described by a fuzzy set. In general, experience and expertise are required for the implementation of fuzzification in complex systems[10] [4].

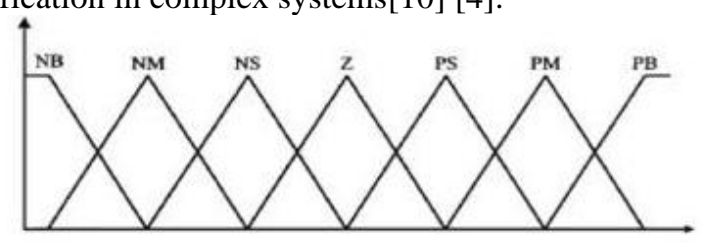

Figure 4.4: Seven levels of fuzzy membership function

Fuzzy logic control doesn't need any difficult mathematical calculation, it only use simple mathematical calculation, but is can provide very good performance in a control system [4]. Thus, it can be one of the best available answers today for a board class of challenging controls problem. A fuzzy logic control consists of:

i. Fuzzification: This process converts or transforms the measured inputs called crisp values, into the fuzzy linguistic values used by the fuzzy reasoning mechanism.

ii. Knowledge Base: A collection of the expert control rules (knowledge) needed to achieve the control goal.

iii. Fuzzy Reasoning Mechanism: This process will perform fuzzy logic operations and result the control action according to the fuzzy inputs.

iv.Defuzzification unit: This process converts the result of fuzzy reasoning mechanism into the required crisp value. 


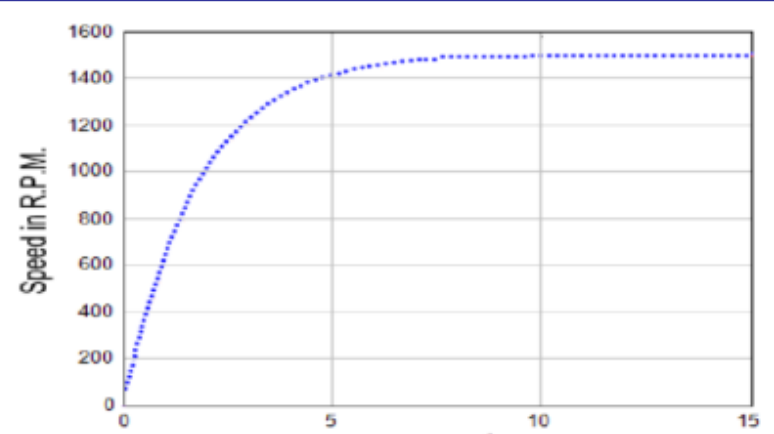

Fig 4.5:Speed Response

The response of the drive system is obtained by setting the reference speed to 1500 r.p.m. This system speed response of fuzzy controller due to the load change and the load reference is 1400r.p.m. Compare to PI controller, it seen no starting overshoot and sudden load change problem for fuzzy logic controller. Fuzzy logic controller provide important advantages over the traditional PI controller like limiting the overshoot in speed, thus the starting current overshoot can be reduced. This paper also demonstrates the successful application of fuzzy logic control to a phase controlled converter dc motor drive. Fuzzy logic was used in the design of speed controllers of the drive system and the performance was compared with that of PI controller. The advantages of the Fuzzy controller are that it determines the number of rules automatically, reduces computational time, learns faster and produces lower errors than other method. By proper design a fuzzy logic controllers is much better then PI controllers for the speed control of dc motor drives.

\section{IV.ANALYSIS}

The corresponding results of the controllers are given,

Table 1: Analysis of Controllers

\begin{tabular}{|c|c|c|}
\hline CONTROLLER & EFFICIENCY & $\begin{array}{l}\text { SETTLING } \\
\text { TIME(Sec) }\end{array}$ \\
\hline PI & LOW & 0.5 \\
\hline $\begin{array}{l}\text { GENETIC } \\
\text { ALGORITHM }\end{array}$ & HIGHER THAN PI & 0.25 \\
\hline $\begin{array}{l}\text { NEURAL } \\
\text { NETWORK }\end{array}$ & $\begin{array}{l}\text { HIGHER THAN } \\
\text { GENETIC } \\
\text { ALGORITHM }\end{array}$ & 0.2 \\
\hline FUZZY LOGIC & $\begin{array}{l}\text { HIGHER THAN } \\
\text { NEURAL } \\
\text { NETWORK }\end{array}$ & 0.05 \\
\hline
\end{tabular}

\section{V.CONCLUSION}

Through this comparison paper we can conclude that Fuzzy logic controllers are more efficient than the PI, Genetic Algorithm and Artificial Neural Network controllers for torque control in PMBLDC motor. High starting overshoot, sensitivity to controller gains and sluggish response due to sudden load disturbance are the main disadvantages of PI controllers. The Genetic Algorithm is proposed as a global optimizer to find the optimized PID gains for control of BLDC motor. ANN (Artificial Neural Network) instead of PI controller because in ANN is faster time response than pi. We are using ANN for better response and reduce the minor errors automatically. Fuzzy logic controller provide important advantages over the traditional PI controller like limiting the overshoot in speed, thus the starting current overshoot can be reduced.

\section{REFERENCES}

[1] S.Mumtaj and C.S. Ravindran, "Sensor less Based Torque Ripple Reduction in Brushless DC Motor", IJITEE 2019.Proceedings of the International Journal of Innovative Technology and Exploring Engineering on, 2019, 2278-3075 vol.9.Issue 2

[2] Vikramarajan Jambulingam, "Speed Control of Brushless DC Motor Using Proportional Integral Controller", IJRASET 2015.Proceedings of the International Journal for Research in Applied Science \& Engineering Technology on 2015, 2321-9653 vol.3.Issue XII.

[3] Thaha H S, Ruban Deva Prakash.T, "Reduction of Power Quality Issues in Micro-Grid using GA Tuned PI Controller Based DVR", (IJITEE), ISSN 2278-3075, Volume- 8, Issue-10 (August 2019) pp. 4166-4172

[4] Tan Chee Siong, Baharuddin Ismail, Mohd Fayzul Mohammed, Mohd Faridun Naim Tajuddin, Siti Rafidah Abd. Rahim, Zainuddin Mat Isa, "Study of Fuzzy and PI Controller For Permanent Magnet Brushless DC Motor Drive", Proceedings of $4^{\text {th }}$ International Engineering and Optimization Conference on 2010, 978-1-4244-7128-7/10/\$26.00@2010 IEEE.

[5] Changliang Xia, Peijian Guo, Tingna Shi andMingchao Wang, "Speed Control of Brushless DC motor using Genetic Algorithm Based Fuzzy Controller", proceedings of the 2004 International Conference on Intelligent Mechatronics and Automation on 2004 0-7803-8748-1/04/\%20.00 02004 IEEE.

[6] Manik Gupta and Shavet Sharma, "GA Tuned PID Controller for Position Control of BLDC Motor", IJEECSE 2018.proceedings of the International Journal of Electrical Electronics \& Computer Science Engineering, 2348-2273 : 2454-1222 vol 5.Issue 4

[7] Er. Darshana Bharti and Dr. Pratibha Tiwari, "Adaptive the Modeling of BLDC Motor Basedon Fuzzy Logic and Genetic Algorithm", IJAREEIE 2018.proceedings of the International Journal of Advanced Research in Electrical, Electronics and Instrumentation Engineeringvol.7. issue10

[8] Tien-Chi Chen, S. H. Shieh and Tsai-Jiun Ren, "Torque Ripple Reduction of Brushless DC Motor Using Genetic Algorithm".Proceedings of the 4th International Conference of Control, Dynamic Systems, and Robotics on 2017.

[9] Niraj Kishore and Surbhi SinghTorque, " Ripples Control and Speed Regulation of Permanent Magnet Brushless dc Motor Drive using Artificial Neural Network", Proceedings of the RAECS on 2014, 978-1-4799-2291-8/14/\$31.00 @2014 IEEE

[10] Thaha, H.S., Ruban Deva Prakash, T."Use of FLC - DVR for Mitigation of Power Quality Issues in Grid \& Composite MicroGrid" Journal of Advanced Research in Dynamical \& Contro Systems, ISSN 1943-023X, Vol. 12, No. 7, 2020: pp. 745-754

[11] Kaushal kishor and sheela tiw, "Speed Control of a Brushless DC motor using NeuralNetwork based MRAC ", proceedings of SARC International Conference on 2017.

[12] Arundhathi Shyam and Febin Daya J L, "A Comparative Study on the Speed Response of BLDC Motor Using Conventional PI Controller, Anti-windup PI Controller and Fuzzy Controller", proceedings of the International Conference on Control

[13] Sreedevi S Nair and Megha pillai, "Simulation of PMBLDC Motor using Artificial Nueral Network",ICIE 2015. Proceedings of the International Conference in Industrial Engineering ICIE, SVNIT, 2015

[14] Thaha, H.S., Ruban Deva Prakash, T. "Use of neural network based DVR for the reduction of power quality issues in composite micro-grid". Journal of Ambient Intelligence and Humanized Computing (2020),ISSN $1868-5137$ https://doi.org/10.1007/s12652- 020-02203-8 